\title{
Occurrence of the Root-Knot Nematode species in Vegetable Crops in Souss Region of Morocco
}

\author{
Soukaina Janati ${ }^{1,2}$, Abdellah Houari ${ }^{1}$, Ahmed Wifaya ${ }^{2}$, Adil Essarioui ${ }^{5}$, Abdelaziz Mimouni ${ }^{2}$, \\ Abderrahim Hormatallah ${ }^{6}$, Mohamed Sbaghi ${ }^{3}$, Abdelfattah A. Dababat ${ }^{4}$, and Fouad Mokrini ${ }^{2 *}$ \\ ${ }^{1}$ Laboratoire des biotechnologies, Faculté polydisciplinaire de Taroudant, Taroudant, Morocco \\ ${ }^{2}$ National Institute of Agronomic Research, UR-Integrated Crop Protection, Nematology Laboratory, National Institute \\ of Agricultural Research (INRA), Agadir, Morocco \\ ${ }^{3}$ National Institute of Agronomic Research-Scientific Division, Rabat, Morocco \\ ${ }^{4}$ International Maize and Wheat Improvement Center (CIMMYIT), Ankara, Turkey \\ ${ }^{5}$ National Institute of Agronomic Research, Errachidia, Morocco \\ ${ }^{6}$ IAV-CHA (Hassan II Institute of Agronomy and Veterinary), Agadir, Morocco
}

(Received on February 12, 2018; Revised on March 22, 2018; Accepted on May 28, 2018)

Root-knot nematodes 'Meloidogyne spp' are the most destructive group of plant parasitic nematodes causeing serious losses in vegetables crops and this damages worsened when crops grown under greenhouses conditions. In this sutdy, the distribution and characterization of root-knot nematode species collected from the Souss region of Morocco where vegetables crops intensively cultivated were determined by using both morphological and molecular tools. Out of the $\mathbf{1 1 0}$ samples collected from different greenhouses $91(81.7 \%)$ were found to be infested with root-knot nematodes. Thirty-seven populations of root-knot nematodes were morphologically identified based on perineal patterns as well as molecularlly using species-specific primers. The obtained results indicated that Meloidogyne javanica and $M$. incognita were identified in $86.4 \%$ and $13.5 \%$ of the total populations, respectively. The lowest incidence of root-knot nematodes $(64 \%)$ was found in Toussous, whereas the highest frequencies of $100 \%$ and $\mathbf{9 0 \%}$ were detected in Taddart and Biogra, respectively. As the majority of the samples have been infested

\footnotetext{
*Corresponding author.

Phone) +212-661-135-696, FAX) +212-528-242-352

E-mail) fmokrini.inra@gmail.com

(c) This is an Open Access article distributed under the terms of the Creative Commons Attribution Non-Commercial License (http:// creativecommons.org/licenses/by-nc/4.0) which permits unrestricted noncommercial use, distribution, and reproduction in any medium, provided the original work is properly cited.
}

Articles can be freely viewed online at www.ppjonline.org. with Meloidogyne species; this indicates that there is an urgent need to provide farmers with a proper control strategy.

Keywords : occurrence, perineal patterns, root-knot nematode, vegetable

Handling Associate Editor : Sang, Mee Kyung

Root-knot nematodes (Meloidogyne spp.; RKN) are the most frequently observed and damaging plant-parasitic nematodes in vegetable production (Jones et al., 2013). Symptoms associated with RKN can be easily diagnosed by farmers due to the presence of distinctive galls on the root systems. RKN infected plants show yellow leaves, stunting growth, nutrient deficiencies symptoms and secondary infections by other pathogens (Hunt and Handoo, 2009). Yield losses depend on the nematode species exists, nematodes initial population, and cultivated crop species (Ornat and Sorribas, 2008). Sasser and Carter (1985) reported yield losses of $22-30 \%$ on tomato due to $M$. incognita infection. In Western Anatolia of Turkey, Meloidogyne spp. caused yield losses of up to $80 \%$ in processing tomatogrowing areas (Kaskavalci, 2007). Similarly, Sikora and Fernández (2005) reported yield losses of over 30\% in three highly susceptible vegetable crops (egg-plant, tomato, and melon). In North-Eastern Spain, the initial nematodes population density of 4750 juveniles of $M$. javanica per $250 \mathrm{~cm}$ of soil caused up to $61 \%$ yield reduction in tomato (Verdejo-Lucas et al., 1994). 
Thirteen new species of Meloidogyne have been described in the last decade; making more than 100 recognized species in this genus (Elling, 2013; Hunt and Handoo, 2009). Out of the 100 identified Meloidogyne species, 22 occur in Africa, posing a significant threat to crop production by small-holder farmers (Karuri et al., 2017).

In Morocco, the RKNs are among the most relevant group of plant parasitic nematodes and are widely distributed throughout the country. Four species namely; $M$. javanica, M. incognita, M. arenaria, and M. hapla have been reported in different agricultural areas of Morocco (Janati et al., 1982) with M. incognita and M. javanica reported as the most common existed species (Janati et al., 1982; Merimi, 1987; Mokrini, 2008; Mokrini, 2016). The Atlantic littoral is the most infested area as vegetable crops are extensively grown in this region and its sandy soil structures makes it preferable for nematode development and reproduction (Janati et al., 1982).

Accurate diagnosis of the RKN to species level is essential for the determination of the most appropriate control strategies to be employed (Coyne et al., 2009). This is especially important when identifying potential sources of host-plant resistance against Meloidogyne species. Diagnosis of species and races of Meloidogyne has always been challenging due to the high similarities in their morphology across species, life stages in different habitats, variable host ranges and intraspecific variability (Blok and Powers, 2009). Species of RKN have been identified based on morphological characters (Eisenback and Triantaphyllou, 1991), host-plant response (Hartman and Sasser, 1985), isozyme analyses (Esbenshade and Triantaphyllou, 1990) and molecular techniques (Adam et al., 2007; Powers and Harris, 1993; Powers et al., 1997; Zijlstra et al., 2000). However, identification by morphological characters is time consuming and require skillful researchers to differentiate among the 100 described species (Hunt and Handoo, 2009), makes the value of many of these characters becomes very questionable, often showing large intraspecific variation and often inconclusive for distinguishing closely related Meloidogyne species, because individuals within a population often vary considerably (Zijlastra et al., 2000). Isozymes analysis is an effective method, which can be carried out on females of Meloidogyne spp. (Esbenshade and Triantaphyllou, 1990). However, application of this method only on female individuals is a limited factor, and can be affected by environmental factors. Recently, molecular tools have been progressively developed for the identification of RKN species (Blok and Powers, 2009). Among these, species-specific DNA protocols have provided fast, accurate and sensitive tools for RKN identification (Adam et al., 2007; Blok and Powers, 2009; Powers and Harris, 1993; Powers, 2004; Tigano et al., 2010; Zijlstra et al., 2000).

To our knowledge, RKN in Morocco have only been identified based on morphological basis and there is no information available in literature about the identification of these RKN populations based on molecular tools. For this reason, we conducted a survey of the major vegetable growing areas in the South region of Morocco, with the following main objectives: (a) to study the distribution of RKN in the South region of Morocco, and (b) to identify RKN populations collected from different localities in the South region of Morocco using both traditional morphological features and molecular techniques.

\section{Materials and Methods}

Sampling and root-knot nematode cultures. A rootknot nematode survey was conducted in 2016 in different vegetable growing areas of Souss region (South of Morocco). Samples were taken from greenhouses located in Biogra, Khmis Ait Amira, Belfaa, Sidi Bibi, Taddart, Toussous (Fig. 1). For each location, 15-20 greenhouses were sampled. A total of 110 soil and root samples were collected. From each greenhouse, 1-2 plants of 3-6 months old and showing RKN infestation symptoms were selected and uprooted to check galls. Infested roots showing galls symptoms were cut with a knife and packed in polyethylene bags along with some soil, labeled and brought to the Nematology Laboratory at the National Institute of Agronomic Research (INRA-Agadir) for species identification. Each sample was labeled with additional information such as; the current cropping system and information about the previous cropping history obtained from the local farmers or the agricultural officer in charge in the corresponding area. Egg masses were picked up individually from infested roots in each greenhouse using a small needle. These egg masses were surface-sterilized in $0.5 \% \mathrm{NaOCl}$ as described by Hussey and Barker (1973) then rinsed in tap water 3 times and prepared for inoculation. Each population was established from a single egg mass and reared on susceptible tomato plant (Solanum lycopersicum, cv. Prystila F1). Tomato seedlings at the fourth true leaf stage were transplanted singly into $500 \mathrm{~mL}$ plastic pots containing sterilized sandy loam soil and sand $(2: 1, \mathrm{v} / \mathrm{v})$ and were allowed to grow for 5-7 days before being inoculated with single egg masses. Plants were maintained in a glasshouse at temperature rate of $25 \pm 5^{\circ} \mathrm{C}$, artificial light of $16 \mathrm{~h}$ per day, and 60 to $90 \%$ of relative humidity. Sixty days after inoculation, plants were removed from pots, root systems 


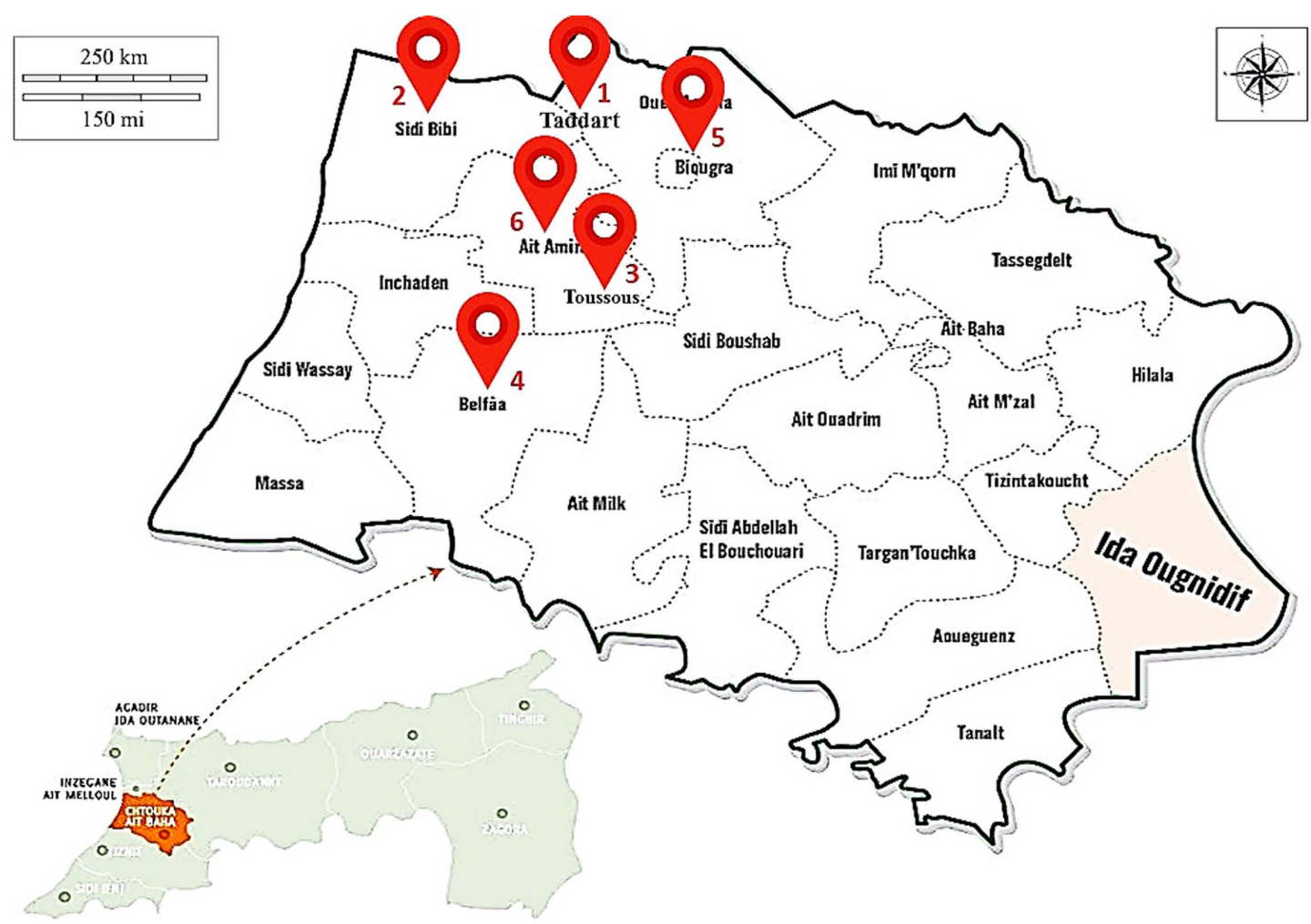

Fig. 1. Map of Souss region of Morocco showing the locations surveyed for RKNs.

were gently washed to free of adhering soil particles, and adult females were extracted from the roots. All populations obtained from single egg masses were renewed by transferring 10 egg masses from each plant into new pots planted with tomato seedlings.

Morphological identification. Morphological identification of the nematode population to species level was performed by using the female perineal pattern method. The females used in the perineal pattern analysis were obtained from those produced from the single egg mass culture aiming to minimize genetic variation. The root tissues were teased apart with forceps and half spear to remove adult females. The head and neck regions of the nematode were excised and the posterior part placed in a solution of $45 \%$ lactic to remove the rest body tissues. From each population, 10 mature females were randomly selected and perineal patterns were prepared and examined under a light microscope according to Eisenback et al (1981).

\section{Molecular Identification}

DNA extraction. To perform the molecular identification, DNA of each nematode population was extracted from 1 to 5 freshly hatched second stage juveniles (J2s). Nematodes were transferred to an Eppendorf tube containing $25 \mu 1$ double distilled water and $25 \mu \mathrm{l}$ nematode lysis buffer (final concentration: $200 \mathrm{mM} \mathrm{NaCl}, 200 \mathrm{mM}$ Tris- $\mathrm{HCl}$ (pH 8), $1 \%$ mercaptoethanol and $800 \mu \mathrm{g}$ Proteinase K). The tubes were incubated at $65^{\circ} \mathrm{C}$ for $1.5 \mathrm{~h}$ and then at $99^{\circ} \mathrm{C}$ for 5 min, consecutively (Holterman et al., 2006). A total of 37 DNA extracts were obtained from the 37 nematode populations (Table 1) and were stored at $-20^{\circ} \mathrm{C}$ until used.

PCR with species-specific primers. Table 2 shows the primers used for DNA analysis of the root-knot nematode species. The quality of the extracted DNA was checked using universal primers developed by Ferris et al. (1993), i.e. forward primer 5'-CGT AAC AAG GTA GCT GTA G-3' and the reverse primer 5'-TCC TCC GCT AAA TGA TAT G-3'. Amplification of the rDNA-ITS region was successful for all populations, and yielded a single band with an expected fragment size of $600 \mathrm{bp}$. All amplification reactions were performed in a final volume of $50 \mu \mathrm{l}$ con-

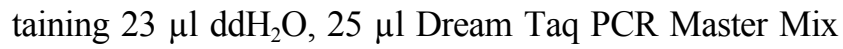
(2x) (Fermentas Life Sciences, Germany), and $1 \mu \mathrm{M}$ of each primer. The program of the thermal cycler consisted of an initial denaturation step at $95^{\circ} \mathrm{C}$ for $5 \mathrm{~min}$, followed by 35 cycles of $30 \mathrm{~s}$ at $95^{\circ} \mathrm{C}, 49^{\circ} \mathrm{C}$ for $45 \mathrm{~s}$ and $72^{\circ} \mathrm{C}$ for 60 $\mathrm{s}$ with a final extension step for $8 \mathrm{~min}$ at $72^{\circ} \mathrm{C}$. Annealing 
Table 1. Occurrence, distribution and control of RKN in vegetable greenhouses in Souss region of Morocco

\begin{tabular}{|c|c|c|c|c|c|c|}
\hline \multirow{2}{*}{$\begin{array}{l}\text { Population } \\
\text { code }\end{array}$} & \multirow[b]{2}{*}{ Location } & \multirow[b]{2}{*}{ Host plant } & \multirow[b]{2}{*}{ Crop rotation } & \multirow[b]{2}{*}{ Control system } & \multicolumn{2}{|c|}{ Species identification } \\
\hline & & & & & Perineal patterns & $\begin{array}{c}\text { Species- } \\
\text { specific PCR }\end{array}$ \\
\hline Bi1 & Biogra & Tomato & Tomato-tomato & Fumigant nematicide + Abamectin & M. javanica (MJ) & MJ \\
\hline $\mathrm{Bi} 2$ & Biogra & Tomato & Tomato-tomato & Fumigant nematicide + Abamectin & M. javanica (MJ) & MJ \\
\hline $\mathrm{Bi} 3$ & Biogra & Tomato & Tomato-tomato & Fumigant nematicide & M. javanica (MJ) & MJ \\
\hline $\mathrm{Bi} 4$ & Biogra & Tomato & Tomato-tomato & Fumigant nematicide & M. javanica (MJ) & MJ \\
\hline $\mathrm{Bi} 5$ & Biogra & Tomato & Tomato-tomato & Fumigant nematicide + Fluopyram & M. javanica $(\mathrm{MJ})$ & MJ \\
\hline K1 & Khmis Ait Amira & Tomato & Tomato-tomato & Fumigant nematicide & M. incognita (MI) & MI \\
\hline $\mathrm{K} 2$ & Khmis Ait Amira & Tomato & Tomato-tomato & Fumigant nematicide + Fluopyram & M. incognita (MI) & MI \\
\hline K3 & Khmis Ait Amira & Tomato & Tomato-tomato & Fumigant nematicide & M. javanica (MJ) & MJ \\
\hline K4 & Khmis Ait Amira & Tomato & Tomato-tomato & Fumigant nematicide + Fluopyram & M. javanica (MJ) & MJ \\
\hline K5 & Khmis Ait Amira & Tomato & Tomato-tomato & Fumigant nematicide + Fluopyram & M. incognita (MI) & MI \\
\hline K6 & Khmis Ait Amira & Tomato & Tomato-tomato & Fumigant nematicide + Abamectin & M.javanica (MJ) & MJ \\
\hline K7 & Khmis Ait Amira & Bean & Tomato-bean & Fumigant nematicide & M. incognita (MI) & MI \\
\hline K8 & Khmis Ait Amira & Tomato & Tomato-tomato & Fumigant nematicide & M. javanica (MJ) & MJ \\
\hline K9 & Khmis Ait Amira & Tomato & Tomato-tomato & Fumigant nematicide + Fluopyram & M. javanica (MJ) & MJ \\
\hline K10 & Khmis Ait Amira & Bean & Tomato-tomato & Fumigant nematicide + Cadusafos & M. javanica (MJ) & MJ \\
\hline K11 & Khmis Ait Amira & Bean & Bean-bean & - & M.javanica (MJ) & MJ \\
\hline K12 & Khmis Ait Amira & Tomato & Tomato-tomato & Fumigant nematicide & M. javanica (MJ) & MJ \\
\hline K13 & Khmis Ait Amira & Tomato & Tomato-tomato & Fumigant nematicide & M. javanica (MJ) & MJ \\
\hline K14 & Khmis Ait Amira & zucchini & Tomato-tomato & Fumigant nematicide & M. javanica (MJ) & MJ \\
\hline K15 & Khmis Ait Amira & Tomato & Tomato-tomato & Fumigant nematicide & M.javanica (MJ) & MJ \\
\hline Be1 & Belfaa (INRA) & Tomato & Tomato-tomato & Abamectin & M. incognita (MI) & MI \\
\hline $\mathrm{Be} 2$ & Belfaa (INRA) & Tomato & Tomato-tomato & Abamectin & M.javanica (MJ) & MJ \\
\hline $\mathrm{Be} 3$ & Belfaa (INRA) & Bean & Bean-bean & - & M. javanica (MJ) & MJ \\
\hline $\mathrm{Be} 4$ & Belfaa (INRA) & Eggplant & Bean- eggplant & - & M. javanica (MJ) & MJ \\
\hline Be5 & Belfaa (INRA) & Tomato & Tomato-tomato & - & M. javanica (MJ) & MJ \\
\hline Be6 & Belfaa & Tomato & Tomato-tomato & Fumigant nematicide & M. javanica (MJ) & MJ \\
\hline $\mathrm{S} 1$ & Sidi Bibi & Tomato & Tomato-tomato & Fumigant nematicide & M. javanica (MJ) & MJ \\
\hline $\mathrm{S} 2$ & Sidi Bibi & Tomato & Tomato-tomato & Fumigant nematicide & M. javanica (MJ) & MJ \\
\hline S3 & Sidi Bibi & Tomato & Tomato-tomato & Fumigant nematicide & M. javanica (MJ) & MJ \\
\hline S4 & Sidi Bibi & Tomato & Tomato-tomato & Fumigant nematicide + Fluopyram & M.javanica (MJ) & MJ \\
\hline S5 & Sidi Bibi & Bean & Tomato-tomato & Fumigant nematicide + Fluopyram & M. javanica (MJ) & MJ \\
\hline Ta1 & Taddart & Tomato & Tomato-tomato & Fumigant nematicide + Abamectin & M.javanica (MJ) & MJ \\
\hline $\mathrm{Ta} 2$ & Taddart & Tomato & Tomato-tomato & Fumigant nematicide & M. javanica (MJ) & MJ \\
\hline Ta3 & Taddart & Tomato & Tomato-tomato & Fumigant nematicide & M.javanica (MJ) & MJ \\
\hline Ta4 & Taddart & Tomato & Melon-tomato & Fumigant nematicide & M. javanica (MJ) & MJ \\
\hline To1 & Toussous & Tomato & Tomato-tomato & Fumigant nematicide + Fluopyram & M. javanica (MJ) & MJ \\
\hline To2 & Toussous & Tomato & Tomato-tomato & Fumigant nematicide + Fluopyram & M. javanica (MJ) & MJ \\
\hline
\end{tabular}

temperatures were set up at $56^{\circ} \mathrm{C}$ for primers Finc/Rinc, $61^{\circ} \mathrm{C}$ for primers $\mathrm{Far} / \mathrm{Rar}$, and $64^{\circ} \mathrm{C}$ for primers Fjav/Rjav. Five microliters of each PCR product was mixed with $1 \mu 1$ of $6 \mathrm{x}$ loading buffer (Fermentas Life Sciences) and loaded on a $1.5 \%$ standard TAE (Tris-Acetate EDTA) buffered agarose gel. After electrophoresis $(100 \mathrm{~V}, 40 \mathrm{~min})$ the gel was stained with ethidium bromide $(1 \mathrm{mg} / \mathrm{l})$ for $20 \mathrm{~min}$, vi- sualised and photographed under UV-light. Negative controls did not contain DNA template; positive controls were run with DNA of the target species

\section{Results}

Distribution of Root-knot Nematodes Species. The re- 
Table 2. Primers used for molecular identification of root-knot nematode (Zijlstra et al., 2000)

\begin{tabular}{|c|c|c|c|}
\hline Name of primer & Species & Fragment (bp) & Primer sequences $(5-3)$ \\
\hline Fjav/Rjav & M. javanica & 670 & $\begin{array}{l}\text { 5'-GGTGCGCGATTGAACCTATAC-3 } \\
\text { 5'-CAGGCCCTTCAGTGGAACTATAC-3' }\end{array}$ \\
\hline Finc/Rinc & M. incognita & 1200 & $\begin{array}{l}\text { 5'-CTCTGCCCAATGAGCTGTCC-3 } \\
\text { 5'-CTCTGCCCTCACATTACG-3 }\end{array}$ \\
\hline
\end{tabular}

Table 3. Incidence of root knot nematodes in different provinces in Souss region of Morocco

\begin{tabular}{ccc}
\hline Provinces & Samples analysed & $\begin{array}{c}\text { Nematode infected } \\
(\%)\end{array}$ \\
\hline Biogra & 20 & $18(90)$ \\
Khmis Ait Amira & 20 & $16(80)$ \\
Belfaa & 20 & $17(85)$ \\
Sidi Bibi & 18 & $13(72)$ \\
Taddart & 15 & $15(100)$ \\
Toussous & 17 & $11(64.7)$ \\
\hline Total & 110 & $91(82.7)$ \\
\hline
\end{tabular}

sults of the survey indicated that root-knot nematodes were present in all surveyed provinces of Souss region (South of Morocco). Out of the 110 studied samples, 91 were found infested with root-knot nematodes.

Distribution of RKN in vegetable greenhouses in the South region of Morocco has been listed in Table 3. The population density of second stage juveniles (J2s) ranged from 59 to 121 per $100 \mathrm{cc}$ soil. The highest levels of infestation were found in Biogra (121 J2 per $100 \mathrm{cc}$ soil). Two species of root-knot nematodes namely $M$. javanica and $M$. incognita were identified on the basis of their perineal pattern and using species-specific primers (Table 1). Out of the 91 samples, $M$. javanica and $M$. incognita occured in 95 and 15 samples representing $86.4 \%$ and $13.5 \%$ of the total populations, respectively. M. javanica was determined as the most common and most widespread nematode species in the South region of Morocco and detected in 32 populations from 6 provinces in which tomato, bean, eggplant and zucchini cultivars were cultivated. In Biogra, Sidi Bibi, Taddart, Toussous provinces, $M$. javanica was the dominant species (100\%). M. incognita was detected only in two provinces (Khmis Ait Amira and Belfaa) within samples collected from tomato and bean fields only.

Perineal pattern identification. Microscopic examination of the perineal pattern morphology of adult females from the different populations revealed the presence of two different species, $M$. javanica and M. incognita. Based on the perineal pattern morphology of the of 32 populations they were classified as $M$. javanica. This made them easy to be separated from those of other populations with the presence of distinct lateral lines. The overall shape of these patterns was rounded and the dorsal arch was generally low. On the other hand, only 5 populations showed the typical $M$. incognita perineal pattern morphology, which is characterized by the presence of a high dorsal arch and wavy striae which bend towards the lateral lines and the absence of distincts lateral line incisures typical of this species.

Molecular characterization. Species-specific primers SCAR were used for molecular characterization of the different RKN populations (Table 2). Amplification of the rDNA- ITS region was successfully performed for all

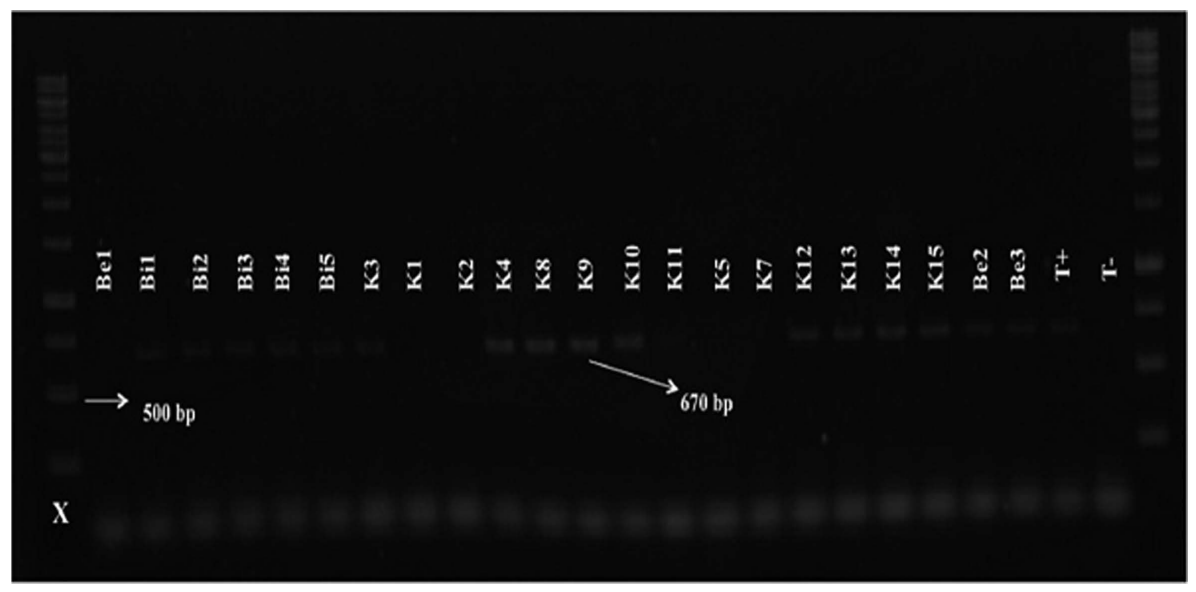

Fig. 2. Amplification product (670 bp) with Fjav/Rjav primers on Meloidogyne population from the Souss region of Morocco. $\mathrm{X}=1 \mathrm{kp}$ DNA ladder; $\mathrm{T}-$ : negative control; $\mathrm{T}+$ : positive control. 


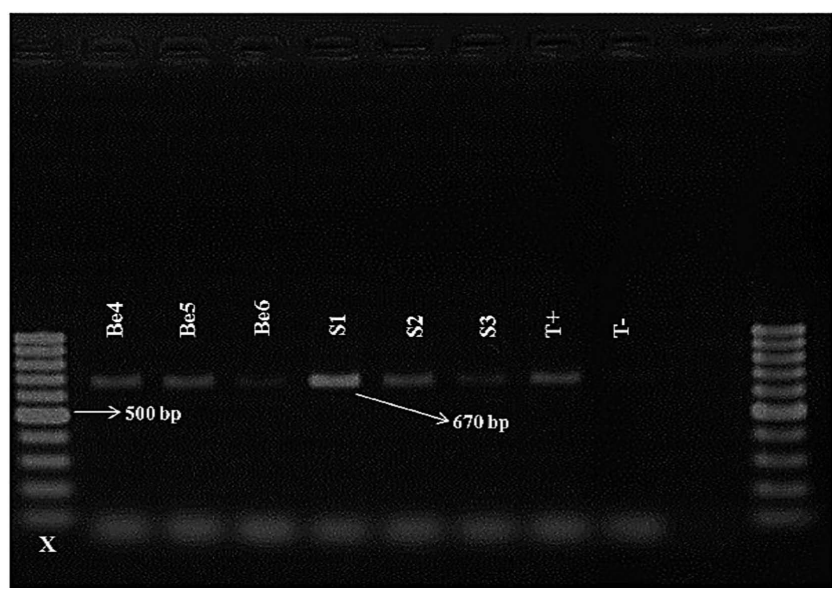

Fig. 3. Amplification product ( $670 \mathrm{bp}$ ) with Fjav/Rjav primers on Meloidogyne population from the Souss region of Morocco. $\mathrm{X}=$ 100 bp DNA ladder; T-: negative control; $\mathrm{T}+$ : positive control

populations and yielded a single band with an expected fragment size of $600 \mathrm{pb}$ (Ferris et al., 1993). No PCR products were obtained from the negative control lacking nematode DNA template. Using the species-specific primers, two RKNs (M. javanica and M. incognita) were identified from the 37 Meloidogyne populations (Table 1). PCR with species-specifc primers for $M$. javanica amplified a band of $670 \mathrm{bp}$ for 32 populations (Figs. 2, 3 and 4). This means that out of 37 samples, 32 samples were molecularly identified as $M$. javanica. For the samples (5 populations) not identified as $M$. javanica, the species-specific primers for $M$. incognita amplified a specific band of 1200 bp (Fig. 4).

\section{Discussion}

The results of the survey demonstrated that RKNs occur in the main vegetables growing areas of Souss region in Morocco. This is similar to that fundings reported by (Bouri-

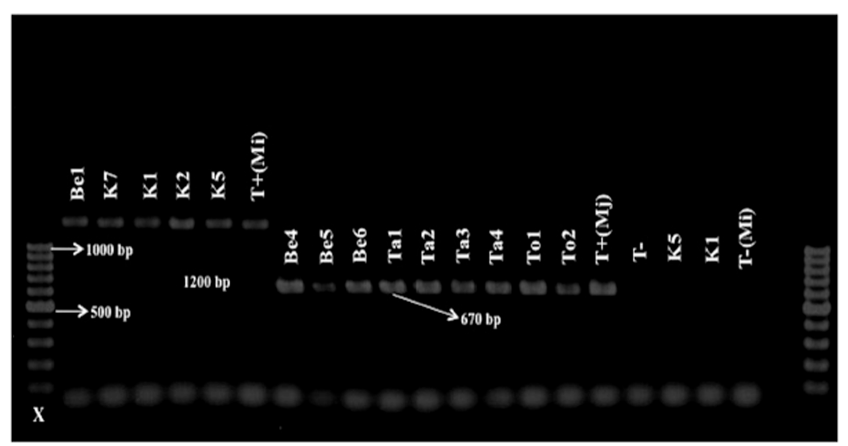

Fig. 4. Results of specific PCR for M. incognita (Be1, K7, K1, K2, K5) and M. javanica (Be4, Be5, Be6, Ta1, Ta2, Ta3, Ta4, To1, To2). $\mathrm{X}=100$ bp DNA ladder (Promega Benelux). T-: negative control; $\mathrm{T}+$ : positive control. jate, 1998; Janati et al., 1982; Mokrini, 2008) indicating the presence of the RKN on vegerables in most prospected areas of Souss region of Morocco. The results from this study showed that the RKNs are widely distributed in the 6 studied provinces with significant variations in incidence among the different provinces. The lowest incidence (64\%) was obtained from Toussous (Table 3), whereas the highest incidences $(100 \%$ and $90 \%)$ were detected in the provinces of Taddart and Biogra, respectively. These proportions of infestation are greater than those observed in earlier surveys from Gharb region (Mokrini, 2008) which can be attributed to environmental factors and agricultural practices. Numbers of Meloidogyne $\mathrm{J} 2$ detected in all surveyed locations were below the damage threshold level for RKN. In this study, the RKN are represented by two species, viz. M. javanica and $M$. incognita. The presence of those Meloidogyne spp. indicates that there is potential damage to vegetables crops and an appropriate management strategies should be seeked and implemented. M. javanica and $M$. incognita are considered very important because they cause severe damage and their wide distribution in the tropical regions (Sikora and Fernandez, 2005). M. javanica is the most prevalent species in the vegetable growing areas of Souss region. It was detected in all provinces in which tomato, bean, eggplant and zucchini are grown. This species was found in $86.4 \%$ of the total populations and was in agreement with that reported from the regions by Oualidia and Souss-Massa. Similarly, Janati et al. (1982) reported that M. javanica was the most common species in Morocco followed by M. incognita, M. arenaria and M. hapla, respectively. The relative importance of $M$. javanica in South of Morocco (Souss region) could be attributed to climate conditions. It has been shown that $M$. javanica is the predominant species in regions with a distinct dry season and if monthly precipitation of less than $5 \mathrm{~mm}$ in three of more successive months (Eisenback et al., 1981). In our study, M. incognita was detected only in $13 \%$ (5 populations) collected from tomato fields (4 populations) and bean crop (1 population) in Khmis Ait Amira and Belfaa provinces. However, M. arenaria and M. hapla were not detected in this study.

Molecular methods provide useful information for species separation and are essential in order to differentiate different species of Meloidogyne (Adam et al., 2007; Zijlstra et al., 2004). In addition to the morphology, species specific primers for PCR have been developed to complement the traditional identification of $M$. javanica (Power and Harris, 1993; Zijlstra et al., 2000; Dong et al., 2001), M. incognita (Dong et al., 2001; Meng et al., 2004; Randig et al., 2002; Tesařová et al., 2003; Zijlstra et al., 2000) and M. arenaria 
(Dong et al., 2001; Zijlstra et al., 2000). When using the species-specific primer developed for both $M$. javanica and M. incognita (Zijlstra et al., 2000) we obtained the characteristic bands of 640 and 1200 bp respectively, confirming their morphological identification. This confirms the specificity of the primer sets. The same primer set was successfully used in other researh (Garcia and Sanchez-Puerta, 2012; Mennan et al., 2011; Toumi et al., 2014; Zijlstra et al., 2000). However, Devran and Söğüt (2009) reported that the primer set (Finc/Rinc) for M. incognita developed by Zijlstra et al. (2000) did not give reproductible amplifications for the populations.

Correct identification of RKN species will lead to provide effective management strategies. As it is difficult to distinguish among all Meloidogyne species by perineal patterns alone due to the considerable variation between and within populations; for the first time we performed both morphological and molecular characterization of RKN species from Souss region of Morocco to 37 populations. This finding is a valuable ressource for future research and for developing effective control and management strategies in the region.

\section{References}

Adam, M. A. M., Philips, M. S. and Blok, V. C. 2007. Molecular diagnostic key for identification of single juveniles of seven common and economically important species of root-knot nematode (Meloidogyne spp.). Plant Pathol. 56:19-197.

Blok, V. C. and Powers, T. O. 2009. Biochemical and molecular identification. In: Root-knot nematodes, ed by R. N. Perry, M. Moens and J. Starr, pp. 98-112. CAB International, Wallingford, UK.

Bourijate, M. 1998. Étude du pouvoir infectieux de Pasteuria penetrans contre Meloidogyne ssp. : Relation entre le parasitisme et la densité des populations et essai de lutte biologique. Thèse de doctorat, University Ibn Zohr, pp. 69. Agadir, Maroc.

Coyne, D. L., Fourie, H. H. and Moens, M. 2009. Current and future management strategies in resource-poor farming. In: Root-Knot Nematodes, ed by R. N. Perry., M. Moens. and J. L. Starr. pp. 444-475. CAB International, Wallingford, UK.

Devran, Z. and Söğüt, M. A. 2009. Distribution and identication of root- knot nematodes from Turkey. J. Nematol. 41:128133.

Dong, K., Dean, R. A., Fortnum, B. A. and Lewis, S. A. 2001. Development of PCR primers to identify species of root-knot nematodes: Meloidogyne arenaria, M. hapla, M. incognita, and M. javanica. Nematropica 31:271-280.

Eisenback, P. R. and Triantaphyllou, H. H. 1991. Root-kont nematodes: Meloidogyne species and races. In: Manual of Agricultural Nematology, ed by W. R. Nickle, pp. 191-274.
Marcell Dekker, New York, USA.

Eisenback, J. D., Hirschmann, H., Sasser, J. N. and Triantaphyllou, A. C. 1981. A guide to the four most common species of root- knot nematodes (Meloidogyne spp.), with a pictorial key. US Agency for International Development, North Carolina, USA. 48 pp.

Elling, A. A. 2013. Major emerging problems with minor Meloidogyne species. Phytopathology 103:1092-1102.

Esbenshade, P. R. and Triantaphyllou, A. C. 1990. Isozyme Phenotypes for the Identification of Meloidogyne Species. J. Nematol. 22:10-15.

Ferris, V. R., Ferris, J. M. and Faghihi, J. 1993. Variation in spacer ribosomal DNA in some cyst-forming species of plant parasitic nematodes. Fundam. Appl. Nematol. 16:177-184.

Garcia, L. E. and Sanchez-Puerta, M. V. 2012. Characterization of a root-knot nematode population of Meloidogyne arenaria from Tupungato (Mendoza, Argentina). J. Nematol. 44:291301.

Hartman, K. M. and Sasser, J. N. 1985. Identification of Meloidogyne species on the basis of differential host test and perineal pattern morphology. In: Advanced Treatise on Meloidogyne. Volume II: Methodology, ed by K. R. Barker., C. C. Carter. and J. N. Sasser, pp. 69-77. North Carolina State University Graphics, Raleigh, USA.

Holterman, M., van der Wurff, A., van den Elsen, S., van Megen, H., Bongers, T., Holovachov, O., Bakker, J. and Helder, J. 2006. Phylum-wide analysis of SSU rDNA reveals deep phylogenetic relationships among nematodes and accelerated evolution toward crown clades. Mol. Biol. Evol. 23:17921800.

Hunt, D. and Handoo, Z. 2009. Taxonomy, identification and principal species. In: Root- knot nematodes, ed by R. N. Perry, M. Moens and J. L. Starr, pp. 55-88. CAP International, London, UK.

Hussey, R. S. and Barker, K. R. 1973. Comparison of methods for collecting inocula of Meloidogyne spp., including a new technique. Plant Dis. Rep. 57:1025-1028.

Janati, A., Aouragh, E. and Meskine, M. 1982. The root-knot nematode. Meloidogyne spp. Third IMP Res. Plan. Conf. Root-knot nematode, Meloidogyne spp. Coimbria, Portugal, 85-93.

Jones, T. J., Haegeman, A., Danchin, E. G., Gaur, H. S., Helder, J., Jones, M. G. K., Kikuchi, T., Manzanilla-Lopez, R., Palomares-Rius, J. E., Wesemael, W. M. L. and Perry, R. N. 2013. Top 10 plant-parasitic nematodes in molecular plant pathology. Mol. Plant Pathol. 14:946-961.

Karuri, H. W., Olago, D., Neilon, R., Mararo, E. and Villinger, J. 2017. A survey of root-knot nematodes and resistance to Meloidogyne incognita in sweet potato varieties from Kenyan fields. Crop Prot. 92:114-121.

Kaskavalci, G. 2007. Effect of soil solarization and organic amendments treatment for controlling Meloidogyne incognita in tomato cultivars in Western Anatolia. Turk. J. Agric. For. 31:159-167. 
Meng, Q., Long, H. and Xu, J. 2004. PCR assays for rapid and sensitive identification of three major root-knot nematodes, Meloidogyne incognita, M. javanica and M. arenaria. Acta Phytopathol. Sinica 34:204-210.

Mennan, S., Aydinli, G. and Kati, T. 2011. First report of rootknot nematode (Meloidogyne arenaria) infecting parsley in Turkey. J. Phytopathol. 159:694-696.

Merimi, Z. 1987. Détermination des espèces de nématodes à galles (Meloidogyne spp.) dans la région de Souss-Massa. Thèse de 3eme cycle pour l'obtention du diplôme d'ingénieur d'état. pp. 71. Agadir, Maroc.

Mokrini, F. 2008. Les nématodes associés aux différentes cultures au Maroc. Rapport de titularisation au sein de l'INRA, pp. 54. Kénitra, Maroc.

Mokrini, F. 2016. Les nématodes de la tomate dans le SoussMassa. Agriculture du Maghreb 93:54-57.

Ornat, C. and Sorribas, F. J. 2008. Integrated management of root-knot nematodes in Mediterranean horticultural crops. In: Integrated Management and Biocontrol of Vegetable and Grain Crops Nematodes, ed by A. Ciancio and K. G. Mukerji, pp. 295-320. Springer, Dordrecht, Netherlands.

Powers, T. O. 2004. Nematode molecular diagnostics: From bands to barcodes. Annu. Rev. Phytopathol. 42:367-383.

Powers, T. O. and Harris, T. S. 1993. A polymerase chain reaction method for identification of five major Meloidogyne spp. J. Nematol. 25:1-6.

Powers, T. O., Todd, T. C., Burnell, A. M., Murray, P. C. B., Fleming, C. C., Szalanski, A. L., Adams, B. A. and Harris, T. S. 1997. The rDNA internal transcribed spacer region as a taxonomic marker for nematodes. J. Nematol. 29:441-450.

Randig, O., Bongiovanni, M., Carneiro, R. M. and CastagnoneSereno, P. 2002. Genetic diversity of root-knot nematodes from Brazil and development of SCAR marker specific for the coffee damaging species. Genome 45:862-870.
Sasser, J. N. and Carter, C. C. 1985. Overview of international Meloidogyne Project 1975-1984. In: An advanced treatise on Meloidogyne. Vol. 1: Biology and control. ed by J. N. Sasser and C. C. Carter, pp. 19-25. State University Graphics, Raleigh, USA.

Sikora, R. A. and Fernandez, E. 2005. Nematode parasites of vegetables. In: Plant-parasitic nematodes in subtropical and tropical agriculture. ed by M. Luc., R. A. Sikora and J. Bridge, pp. 319-392. CABI Publishing, Wallingford, UK.

Tesařová, B., Zouhar, M. and Ryšánek, P. 2003. Development of PCR for specific determination of root-knot nematode Meloidogyne incognita. Plant Protect. Sci. 39:23-28.

Tigano, M., De Siqueira, K., Castagnono-Sereno, P., Mulet, K., Queiroz, P., Dos Santos, M., Teixeira, C., Almeida, M., Silva, J. and Carneiro, R. 2010. Genetic diversity of the root-knot nematode Meloidogyne enterolobii and development of a SCAR marker for this guava-damaging species. Plant Pathol. 59:1054-1061.

Toumi, F., Waeyenberge, L., Yousef, R., Khalil, H., Al-Assas, K. and Moens, M. 2014. Distribution of the root-knot nematode Meloidogyne spp., in tomato greenhouses at Lattakia and Tartus Province in Syria. Pak. J. Nematol. 32:163-172.

Verdejo-Lucas, S., Sorribas, J. and Puigdomenech, P. 1994. Yield losses caused by Meloidogyne javanica on lettuce and tomato in a plastic house. Invest. Agrar. Prod. Prot. Veg. Suppl. 2:395-400.

Zijlstra, C., Donkers-Venne, D. T. H. M. and Fargette, M. 2000. Identification of Meloidogyne incognita, M. javanica and $M$. arenaria using sequence characterised amplified region (SCAR) based PCR assays. Nematology 2:847-853.

Zijlstra, C., Van Hoof, R. and Donkers-Venne, D. 2004. A PCR test to detect the cereal root-knot nematode Meloidogyne naasi. Eur. J. Plant Pathol. 110:855-860. 